Short Communication

\title{
Comparison of Ethanol Gas Sensors based on PbS nanoparticles and Bulk PbS
}

\author{
A.K. Mishra, S.Saha \\ Department of physics, Vidyasagar University, Paschim Medinipur, West Bengal, PIN 721102, India \\ "E-mail: anjanmishra2011@gmail.com
}

doi: $10.20964 / 2020.11 .42$

Received: 22 May 2020 / Accepted: 4 September 2020 / Published: 30 September 2020

\begin{abstract}
An attempt is made to fabricate the ethanol gas sensor at room temperature. A cost-effective and simple chemical reduction route is used to grow cubic and spherical $\mathrm{PbS}$ nanoparticles using Ethylene Diamine as a capping agent. Bulk $\mathrm{PbS}$ is grown by a simple chemical method without using any capping agent. Structural characterization of samples is done by X-ray diffraction (XRD), transmission electron microscopy(TEM), and scanning electron microscopy(SEM). Optical characterization is done by UVVisible-NIR absorption spectroscopy. The gas sensor is fabricated based on cubic, spherical $\mathrm{PbS}$ nanoparticles, and bulk PbS. Sensitivity measurement is done at room temperature for ethanol gas by three types of sensors. Ethanol gas Response, Response time, and Recovery time are calculated for different shapes of $\mathrm{PbS}$ nanoparticles and bulk $\mathrm{PbS}$. Gas sensitivity is found to be high for sensor-based on spherical PbS nanoparticles and is less for sensors based on bulk PbS.
\end{abstract}

Keywords: Lead Sulfide, Nanoparticles, X-Ray diffraction, Gas Sensor, Ethanol, Sensitivity.

\section{$\underline{\text { FULL TEXT }}$}

(C) 2020 The Authors. Published by ESG (www.electrochemsci.org). This article is an open access article distributed under the terms and conditions of the Creative Commons Attribution license (http://creativecommons.org/licenses/by/4.0/). 